\title{
ANALISIS PENGGUNAAN FILM DALAM PENINGKATAN PEMAHAMAN BAHASA CHINA MAHASISWA
}

\author{
Mariana; Xuc Lin \\ Chinese Department, Faculty of Humanities, Bina Nusantara University \\ Jln. Kemanggisan Ilir III No. 45, Palmerah - Kemanggisan, Jakarta Barat 11480 \\ mar14na@binus.ac.id, basenji88@yahoo.com
}

\begin{abstract}
Article explored to what extent students from the Chinese Department, Bina Nusantara University, were able to comprehend Mandarin language through "Home wih Kids" film. Qualitative method was applied by doing observation in class using prepared learning materials got from the film. There were 27 respondents coming from two classes. They were students from semester 1 who took Listening class. The writter also applied observation approach by distributing questionaires to students to know their comprehension of the film content. It can be concluded that students tend to be more enthusiastic in learning Chinese language by using film, and they are able to do the questions and retelling the plot of the film. This evidences prove that the influence of film gives more advantages to develop Chinese language proficiency of the Chinese department students, Bina Nusantara University.
\end{abstract}

Keywords: language comprehension, Chinese language, film

\begin{abstract}
ABSTRAK
Artikel bertujuan untuk mengetahui seberapa jauh mahasiswa Jurusan Sastra China, Universitas Bina Nusantara, memahami bahasa Mandarin melalui film "Home with Kids". Metode penelitian yang digunakan adalah kualitatif berupa observasi pengajaran kosakata dengan materi yang disiapkan berdasarkan film tersebut. Responden adalah 27 mahasiswa semester satu dari dua kelas yang mengambil mata kuliah Listening. Selain itu, observasi dilakukan dengan memberikan kuesioner terkait pemahaman film tersebut kepada responden. Disimpulkan, mahasiswa cenderung lebih antusias dalam mempelajari bahasa China menggunakan film dan mereka mampu untuk mengerjakan latihan dan menguraikan isi cerita sesuai dengan isi film. Hal ini membuktikan bahwa pengaruh film sangat bermanfaat untuk peningkatan bahasa China pada mahasiswa jurusan Sastra China, Universitas Bina Nusantara.
\end{abstract}

Kata kunci: pemahaman bahasa, bahasa Mandarin, film 


\section{PENDAHULUAN}

Tobias (2009:7) mengatakan: "Setiap manusia memiliki cara berbeda untuk memahami ataupun menguasai sesuatu, yang disebut gaya belajar." Bermacam gaya belajar yang dikenal, yaitu gaya belajar visual. Gaya ini menitikberatkan pada ketajaman penglihatan. Ada orang tertentu yang lebih bisa mengingat sesuatu apabila dia melihat langsung bagaimana proses kejadian itu berlangsung. Biasanya, orang semacam ini cenderung mampu menggambarkan informasi dalam bentuk gambar, diagram, grafik, flow chart dan simbol visual seperti panah, lingkaran, hierarki, dan materi lain yang digunakan instruktur untuk mempresentasikan hal-hal yang dapat disampaikan dalam kata. Hal ini mencakup juga desain, pola, bentuk, dan format lain yang digunakan untuk menandai dan menyampaikan informasi. Manusia yang belajar secara visual umumnya menyukai intruksi berupa tulisan dan foto. Selain dari itu, mereka juga suka menggunakan gerakan tubuh untuk mengekspresikan atau mengganti sebuah kata saat mengungkapkan sesuatu. Mereka juga cenderung dapat mengingat informasi yang diberikan secara lisan ataupun gambaran yang nyata. Metode pengajaran yang cocok untuk diterapkan bagi manusia yang belajar secara visual ialah gambar atau video.

Berikutnya adalah manusia yang belajar menggunakan metode cara auditory. Manusia yang seperti ini umumnya mengandalkan pendengaran dalam menguasai atau mempelajari sesuatu. Manusia yang seperti ini umumnya mampu menyerap informasi dan pengetahuan melalui ceramah, pidato, tutorial, diskusi kelompok, ataupun membicarakan materi secara langsung. Keunggulan manusia yang menguasai teknik belajar dengan auditori ialah kemampuan untuk mengingat setiap kata meskipun kata tersebut bukan keluar dari mulut mereka sendiri. Selain dari pada itu, orang seperti ini cenderung menyukai acara diskusi kelompok atau seminar. Metode pengajaran yang cocok untuk diterapkan kepada manusia yang belajar secara auditori adalah hadir di dalam kelas, mendengarkan penjelasan guru, selain dari itu mendiskusikan ide atau pemikiran yang terlintas dalam pikiran mereka.

Yang terakhir adalah manusia yang belajar dengan menggunakan metode kinestetik. Manusia seperti umumnya mampu menguasai suatu bidang atau pengetahuan dengan mempraktikkan bidang tersebut. Umumnya, manusia seperti ini cenderung tidak menyukai hal yang bersifat teoretis. Dia lebih menyukai latihan dan praktik lapangan langsung untuk memahami dan menguasai sesuatu. Manusia yang seperti ini cenderung menggunakan seluruh indera untuk memahami teori atau ilmu bidang yang sedang dipelajari.

McDonald (2005:33) menjelaskan, "Film merupakan sarana multimedia yang sudah ada dari zaman dahulu. Film selain digunakan sebagai sarana hiburan ternyata juga memiliki peran penting dalam mengajarkan seseorang untuk memahami sesuatu." Manusia umumnya lebih cenderung memahami sesuatu dengan cara melihat dan mendengar langsung. Menurut Liu dan Deng (2009:10), film "Home with Kids" menceritakan kehidupan keluarga China dan bagaimana cara orang tua mendidik anak mereka dalam kehidupan seharihari. Selain menceritakan kehidupan sehari-hari, film ini juga menonjolkan budaya China yang telah mengalami perubahan akibat perkembangan zaman. Banyak istilah atau kata baru dalam film ini yang bagus untuk diketahui. Selain itu, dalam film ini juga terdapat konflik rumah tangga dan cara mereka menyelesaikan. Itulah sebabnya film ini menjadi sangat menarik dan dijadikan salah satu materi pembelajaran di China pada zaman sekarang.

Home with Kids merupakan film bergenre keluarga yang menceritakan cara orang tua mendidik anak mereka. Home with Kids episode 1 menceritakan suatu rumah tangga yang baru saja dibangun kembali melalui sebuah pernikahan kedua antara tokoh utama pria Xia Donghai dan tokoh utama wanita Liu Mei. Keduanya samasama menjalani pernikahan mereka yang kedua dengan membawa anak mereka masing-masing. Episode 1 menceritakan anak pertama Xia Donghai, yaitu Xia Xue yang baru masuk ke dalam rumah tangga baru mereka. Dia memiliki persepsi negatif terhadap ibu tirinya karena sang ayah tidak memberitahukan terlebih dahulu perihal pernikahan kedua tersebut. Hal ini menyebabkan Xia Xue mengalami pergolakan dalam menerima kehadiran Liu Mei. Berbagai cara dilakukan Xia Xue untuk menguji ketulusan Liu Mei dalam menerima kehadirannya. Selain perseteruan dan konflik antara Liu Mei dan Xia Xue, cerita juga diwarnai kejenakaan yang dilakukan oleh Liu Xing dan Xia Yu, anak kedua Liu Mei dan anak kedua Xia Donghai sehingga film ini menjadi lebih berwarna dan menarik untuk ditonton oleh mahasiswa.

Penelitian mengkaji secara khusus kemampuan mahasiswa jurusan Sastra China dalam memahami makna Home with Kids serta bagaimana cara mahasiswa mempelajari budaya China dan menerapkan penggunaan bahasa dalam film ke dalam kehidupan sehari-hari. Cakupan penelitian adalah film Home with Kids dan penggunaan materi buku Home with Kids. Selain itu, penulis hanya meneliti mahasiswa tahun pertama jurusan sastra China Binus University. Pada tahun pertama mahasiswa sedang fokus untuk memperdalam kemampuan berbicara dan mendengar bahasa Mandarin. Penelitian difokuskan pada film Home with Kids dengan 27 responden, yaitu mahasiswa jurusan sastra China Binus University sebagai objek penelitian. Masa penelitian ialah 1 semester yaitu semester ganjil 2014/2015 hingga pertengahan menjelang UTS semester ganjil 2014/2015

\section{METODE}

Penelitian menggunakan metode kualitatif. Studi pustaka dilakukan dengan mencari informasi dari buku teks, artikel, dan laporan penelitian yang berkaitan dengan metode pengajaran bahasa China. Pengumpulan data film Home with Kids dilakukan dengan menyaring kosakata dan tata bahasa yang terdapat dalam film. Selanjutnya, latihan yang sesuai dengan isi film dibuat. Setelah semua materi tersusun rapi, rencana pengajaran dibuat yang berfungsi untuk mengatur jalannya proses penelitian.

Setelah mendalami isi film, observasi dilakukan dengan memberikan bahan dan rencana pengajaran di kelas kepada mahasiswa semester 1 dengan langkah berikut. Pertama-tama kosakata yang terdapat dalam film 
dijelaskan terlebih dahulu, setelah itu film Home with Kids Episode 1 ditayangkan. Setelah selesai menyaksikan film mahasiswa diminta mengerjakan latihan yang telah disiapkan. Setelah berkas latihan dikumpulkan, isi dari cerita film dijelaskan kembali sehingga mahasiswa dapat memahami isi dan jalan cerita Home with Kids Episode 1.

Hasil dan nilai latihan diolah sebagai dasar analisis penelitian. Metode kuantitatif dilakukan dengan membagi kuesioner kepada mahasiswa untuk mengetahui manfaat dari menonton film terhadap perkembangan bahasa China. Responden penelitian adalah mahasiswa jurusan sastra China, Universitas Bina Nusantara sebanyak 2 kelas yaitu kelas LC63 yang berjumlah 17 anak dan kelas LD63 yang berjumlah 10 anak. Waktu penelitian adalah satu semester, yaitu semester ganjil 2014/2015 hingga pertengahan menjelang UTS semester ganjil 2014/2015

\section{HASIL DAN PEMBAHASAN}

In the study, Materi yang digunakan ialah film Home with Kids yang menggunakan bahasa sehari-hari dengan logat Beijing, penampilan pemain yang alami dan lancar, serta penggunaan bahasa sehari-hari yang sering ditemui dalam masyarakat China. Menurut Stempleski dan Tomalin (2001) ada tiga cara untuk menjalankan kelas film sehingga bisa berlangsung dengan sukses, yaitu seleksi film, pilihan aktivitas atau latihan, dan implementasi ke mahasiswa. Dalam film Home with Kids, penuturan kalimat yang disampaikan tokoh juga jelas dan mereka banyak menggunakan istilah keseharian yang berkaitan dengan kehidupan zaman sekarang pada masyarakat China. Itulah sebabnya penulis memilih film Home with Kids sebagai materi yang akan diberikan kepada mahasiswa.

Selain film yang jelas dan menarik, Home with Kids dipilih sebagai materi ajar karena sudah memiliki buku panduan pengajaran di China. Film tersebut juga digunakan oleh Beijing University dan Beijing Language and Culture University sebagai materi untuk mengajar mahasiswa asing. Tambahan pula, film ini juga memaparkan budaya China yang dengan mudah dapat dipahami oleh mahasiswa.

Sasaran pengajaran adalah mahasiswa semester 1 jurusan Sastra China kelas LC63 dan LD63 dalam mata kuliah CHIN6088 Listening 1. Mahasiswa semester 1 dipilih karena mereka dalam mata kuliah Listening 1 memiliki bobot SKS 4, sehingga dimungkinkan untuk melakukan penelitian di sela-sela materi perkuliahan yang sedang berjalan. Selain itu, mahasiswa semester 1 adalah mahasiswa yang baru pertama kali masuk, sehingga dimungkinkan dapat memperoleh hasil maksimal akan proses pengajaran yang akan diterapkan karena mereka masih bersemangat tinggi.

Proses pengajaran dilakukan di Bridging Campus, Alam Sutra, ruang ASB29 dan kampus Anggrek ruang 614 karena di dalam ruangan tersebut terdapat perangkat audio visual yang mendukung pengajaran bahasa, seperti komputer dengan program sodic, speaker, dan headset yang membuat mahasiswa tidak mengalami kendala selama proses pemutaran film berlangsung.

Isi materi yang diambil dari Home with Kids episode 1 世界图书 adalah
Kosakata

$\begin{array}{ll}\text { 瞧 } & \text { qiáo (v); look } \\ \text { 亲 } & \text { qīn (adj); related by blood } \\ \text { 兄弟 } & \text { xiōngdì (n) brother } \\ \text { 似的 } & \text { shìde (part); like } \\ \text { 干脆 } & \text { gāncuì (adv); simply } \\ \text { 赶 } & \text { găn (v); drive away } \\ \text { 轰 } & \text { hōng (v); drive off } \\ \text { 闺女 } & \text { guīnü (n); daughter } \\ \text { 至于 } & \text { zhìyú (adv) go so far as to } \\ \text { 正式 } & \text { zhèngshì (adj); formal } \\ \text { 自打 } & \text { zìdá (prep); since } \\ \text { 品味 } & \text { pĭnwèi (n); quality } \\ \text { 帅 } & \text { shuài (adj); handsome } \\ \text { 重症病房 zhòngzhéngbìngfáng; ICU } \\ \text { 光辉 } & \text { guānghuī (adj); glory }\end{array}$

Menurut Liu dan Deng (2009:13)

跟.......似的

像...... 一样。“似的”是助词，用在名词、代词 或动词后，表示跟某种事物或情况类似。

跟......似的 sama artinya dengan像..... 一样 dan

似的. Mereka merupakan kata bantu. Biasanya mereka terletak dibelakang kata benda, kata ganti ataua kata kerja. Mengandung makna bahwa objek yang ditunjuk menyerupai benda atau kondisi tertentu.

Contoh kalimat:

- 你瞧, 咱俩结婚刚两个月, 这俩孩子就好得跟 亲兄弟似的，多好啊！

- 他们俩长得跟亲姐妹似的。

多......啊

“多”用于感叹句，表示程度高。一般句式是“ 多 + 形容词 + (啊) ”。在口语中, “啊”常常前边 的词语尾音发生音变, 变成“哪”、“呀”、“哇”等。书 写时可以不变。

“多”biasanya digunakan dalam kalimat seru, mengandung makna tingkatan yang sangat tinggi. Biasanya dalam kalimat, pola penyusunanya terdiri dari “多”+ kata sifat + “啊”, “啊” dalam percakapan sering terjadi perubahan bunyi menjadi “哪”、“呀”、“ 哇”dsb. Namun dalam kalimat baku atau tulisan huruf “ 啊”tidak mengalami perubahan.

Contoh kalimat:

- 你瞧, 咱俩结婚刚两个月, 这俩孩子就好得跟 秦兄弟似的，多好啊！

- 这里的空气多新鲜啊。

\section{干脆}

副词, 索性。由于前边所说的情况或者双方都 知道的情况比较麻烦, 所以采取一个比较简单的方法 或者作出一个容易操作的决定。

“干脆”merupakan adverb (kata keterangan). Biasanya, kalimat awal di kondisi atau kejadian lebih rumit, sehingga menyebabkan di kalimat kedua pihak yang berbicara mengambil keputusan untuk mempermudah kondisi atau keadaan dengan mengambil tindakan yang lebih ringkas. 
Contoh kalimat:

- 我是说啊, 干脆把夏雪从她爷爷家也结果来一 快儿住。

- 冰箱里没有东西了? 干脆去饭馆吃吧。

不就......嘛, 至于 ......吗?

只是一个简单的事情, 到不了那么严重的程

度。对所说的人、事往小里说或者表示轻视。

“不就 ......嘛, 至于......吗? ”digunakan untuk menunjukkan bahwa kondisi atau orang yang sedang ditunjuk tidak terlalu sulit dihadapi atau tinggi tingkatannya. Pembicara dalam hal ini memperkecil objek orang atau masalah yang dibicarakan atau bisa dikatakan meremehkan objek tersebut.

Contoh kalimat:

- 不就是借个闺女嘛，至于这么正式吗？

- 不就是一支蜘蛛嘛, 至于这么怕吗?

- 不就是一词考试嘛, 至于这么紧张吗?

A对B有信心

相信某人能做好某事，或相信某事能取得好结 果。

“A对B有信心” mengandung makna, percaya akan seseorang dapat mengerjakan dengan baik suatu masalah, atau percaya bahwa suatu kejadian akan memperoleh hasil yang memuaskan.

Contoh kalimat:

- 我对你有信心。

- 我对这次比赛很有信心。

・我对自己没信心。

\section{$\mathrm{A}$ 被B（给）}

被动句。“被”引进动作的施事, $\mathrm{A}$ 是动作的受 动者; “给”在这里是助词, 直接用在动词前, 也可以 省略。

“A被B (给)” merupakan struktur kalimat pasif. “被”menjelaskan bahwa A merupakan pelaku yang menyebabkan B terkena dampak atau akibat. Kata “给”di sini hanya sebagai pelengkap yang boleh ada atau dihilangkan. Di belakang kalimat biasanya diakhiri dengan kata kerja.

Contoh kalimat:

- 妈, 我的手被虫子给咬了。

- 我的衣服被雨（给）淋湿了。

- 我的车被朋友 (给) 接走了。

Melalui pengajaran ini diharapkan mahasiswa dapat menganalisis isi cerita, menjelaskan isi cerita, menjawab pertanyaan yang diberikan, serta menceritakan ulang isi cerita dengan menggunakan bahasa China.

Strategi pengajaran menjelaskan langkah yang akan diambil dalam pengajaran di dalam kelas. Pengajaran akan berlangsung selama 100 menit, dengan urutan berikut. Bagian pertama menjelaskan kosakata (10 menit). Sebelum mulai menjelaskan kosakata, terlebih dahulu akan dipaparkan topik dengan memaparkan isi film sesuai kondisi nyata. Setelah itu, mahasiswa secara acak diminta untuk membuat kalimat dengan menggunakan kosakata baru yang diberikan. Bagian kedua menjelaskan tata bahasa (20 menit). Tahap berikutnya adalah menjelaskan tata bahasa yang akan digunakan dalam film. Jika mahasiswa tidak ada pertanyaan dan sudah memahami kosakata dan tata bahasa yang ada, pemutaran film dimulai. Bagian ketiga, mahasiswa menyaksikan film (26 menit). Mahasiswa menyaksikan film berdurasi 25,08 menit sebanyak satu kali. Bagian keempat, mahasiswa mengerjakan latihan (10 menit). Mahasiswa mulai mengerjakan latihan secara mandiri dan mengumpulkan soal latihan begitu sudah selesai dijawab semua. Dalam kasus ini dipilih dua model latihan, yang pertama adalah menarik garis dan yang kedua adalah pilihan ganda. Bagian kelima, mahasiswa memaparkan isi cerita dalam bentuk lisan (15 menit). Mahasiswa yang dipilih secara acak memaparkan ulang isi cerita dalam bentuk lisan. Tujuan bahasan adalah agar mahasiswa yang kurang mengerti dapat lebih mengerti isi cerita yang dipaparkan. Bagian keenam, penjelasan isi cerita (15 menit). Bersamaan dengan uraian yang diberikan mahasiswa secara lisan, pengajar yang juga peneliti akan memperbaiki bagian yang salah dijelaskan oleh mahasiswa, selain peneliti juga menjelaskan secara terperinci seluruh uraian cerita yang sebenarnya.

Respons mahasiswa dapat dilihat dari dua hal, yaitu hasil latihan yang dikerjakan mahasiswa dan cara mahasiswa memaparkan isi cerita. Dari kedua hal tersebut bisa diambil respons mahasiswa terhadap pengajaran bahasa menggunakan media film tersebut. Hasil latihan mahasiswa dinilai berdasarkan new grading system for binusian 2018 dengan hasil yang ditunjukkan pada Tabel 1 dan 2.

Tabel 1 menunjukkan bahwa dari 17 mahasiswa terdapat 10 mahasiswa memperoleh nilai Good dan 5 mahasiswa memperoleh nilai Excellent dalam latihan tes tertulis. Ini membuktikan bahwa sebagian besar mahasiswa lebih mudah menyerap materi pelajaran dengan menggunakan multimedia film. Hasil ini menguatkan bahwa latihan menggunakan multimedia film sangat bermanfaat untuk meningkatkan kemampuan mahasiswa dalam mempelajari bahasa China.

Sedangkan Tabel 2 menunjukan bahwa dari 10 mahasiswa kelas LD63, terdapat 5 orang mahasiswa yang memperoleh nilai Excellent dan 3 orang mahasiswa memperoleh nilai Good. Ini membuktikan bahwa sebagian besar mahasiswa dapat mengerti isi cerita film, terlebih lagi penulis menyadari bahwa mahasiswa terlihat antusias pada saat menceritakan ulang isi film. Hal ini membuktikan bahwa penggunaan multimedia film di dalam kelas sebagai sarana untuk meningkatkan kemampuan mahasiswa dalam meningkatkan bahasa China cukup efektif.

Selain menggunakan sesi soal ujian, penulis juga menggunakan sesi tanya jawab dan diskusi. Hasil yang diperoleh menunjukkan $85 \%$ dari 27 orang mahasiswa memahami keseluruhan isi cerita dan dapat menceritakan ulang isi cerita. Mahasiswa-mahasiswa tersebut mendapat nilai Good dan Excellent untuk sesi tanya jawab. Sedangkan $15 \%$ dari 27 orang mahasiswa merasa bahwa dialog dalam film cenderung cepat dan sulit dimengerti, sehingga mereka memperoleh nilai fair. Bahkan, mereka tidak dapat menceritakan ulang keseluruhan isi film. (Gambar 1) 
Tabel 1 Hasil Tes Mahasiswa Kelas LC63

\begin{tabular}{|c|c|c|c|c|c|}
\hline NO & NAMA & NIM & NILAI & $\begin{array}{l}\text { LETTER } \\
\text { GRADET5 }\end{array}$ & DESKRIPSI \\
\hline 1 & Feny Kartika Sari & 1801398460 & 100 & A & Excellent \\
\hline 2 & Erika Juliati & 1801401155 & 77 & B & Good \\
\hline 3 & Indriani Gazela & 1801403974 & 77 & B & Good \\
\hline 4 & Devi Siswani & 1801405014 & 77 & B & Good \\
\hline 5 & $\begin{array}{l}\text { Adila Atika } \\
\text { Rahman }\end{array}$ & 1801408104 & 77 & B & Good \\
\hline 6 & $\begin{array}{l}\text { Raga Randiza } \\
\text { Anugrah }\end{array}$ & 1801418925 & 85 & A- & Excellent \\
\hline 7 & Jeanette & 1801419165 & 85 & A- & Excellent \\
\hline 8 & Thalia Pangesti N & 1801420122 & 65 & $\mathrm{C}$ & Fair \\
\hline 9 & Angeline Calista & 1801420665 & 76 & B & Good \\
\hline 10 & Lucia Anggriana & 1801425773 & 92 & A & Excellent \\
\hline 11 & Astrid Prakasa & 1801432601 & 73 & B- & Good \\
\hline 12 & Tiara Cornelia W & 1801432614 & 81 & $\mathrm{~B}+$ & Excellent \\
\hline 13 & $\begin{array}{l}\text { Agatha Virgilia } \\
\text { Nogo }\end{array}$ & 1801432620 & 75 & B & Good \\
\hline 14 & Feny Feronica & 1801432910 & 76 & B & Good \\
\hline 15 & Zefanya Priscilla & 1801433056 & 70 & B- & Good \\
\hline 16 & $\begin{array}{l}\text { Devina Diamanta } \\
\text { S W }\end{array}$ & 1801434336 & 65 & $\mathrm{C}$ & Fair \\
\hline 17 & Regent & 1801444772 & 73 & B- & Good \\
\hline
\end{tabular}

Tabel 2 Hasil Tes Mahasiswa Kelas LD63

\begin{tabular}{clcccc}
\hline NO & \multicolumn{1}{c}{ NAMA } & NIM & NILAI & $\begin{array}{c}\text { LETTER } \\
\text { GRADET5 }\end{array}$ & DESKRIPSI \\
\hline 1 & Raisa Goldatama & 1701361705 & 68 & C & Fair \\
2 & Risa Goretty & 1701361964 & 68 & C & Fair \\
3 & Tiana Gracia & 1801383146 & 86 & A- & Excellent \\
4 & Hendro Trijaya & 1801383272 & 75 & B & Good \\
5 & Jessica & 1801398091 & 70 & B- & Good \\
6 & Ratu Hana Taruna & 1801407966 & 85 & A- & Excellent \\
7 & Novita Winda & 1801417784 & 85 & A- & Excellent \\
8 & William Nodas & 1801423710 & 88 & A- & Excellent \\
9 & Irene Laurina & 1801426643 & 85 & A- & Excellent \\
& Jermias & & & & B \\
\hline 10 & Patricia Suryadiky & 1801428705 & 77 & & \\
\hline
\end{tabular}

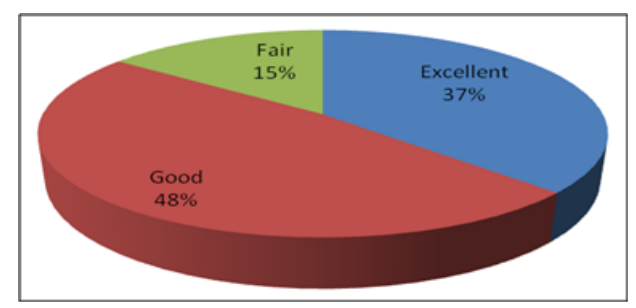

Gambar 1 Hasil Tes Keseluruhan Mahasiswa

Berdasarkan analisis data, mahasiswa dapat dengan mudah memahami isi film. Selain itu, bantuan penjelasan kosakata dan tata bahasa di awal pertemuan menyebabkan mahasiswa mudah mempraktikkan tata bahasa dan kosakata untuk menjelaskan isi film. Hal ini membuktikan bahwa film dapat merangsang kemampuan mahasiswa dalam berbicara bahasa China.

\section{SIMPULAN}

Penelitian membuktikan bahwa respons mahasiswa menunjukkan bahwa mereka lebih efektif mempelajari bahasa China dengan bantuan film. Hal ini ditunjukkan dengan nilai Good yang diperoleh sebagian besar mahasiswa yang juga membuktikan bahwa mahasiswa memahami isi film dan dapat mengerjakan latihan yang diberikan. Sedangkan melalui respons mahasiswa yang berbentuk penjelasan, juga dapat diketahui bahwa mahasiswa mampu menjelaskan isi film, baik itu menggunakan bahasa China ataupun bahasa Indonesia. Selain itu, mahasiswa juga mampu langsung mempraktikkan tata bahasa yang berkaitan dengan isi film, terutama tata bahasa yang telah dijelaskan di awal pertemuan. Hal ini membuktikan bahwa penggunaan multimedia film bermanfaat untuk meningkatkan kemampuan bahasa China mahasiswa.

\section{DAFTAR PUSTAKA}

Jiang, M.(2010). Duiwai hanyu tingli jiaoxue de jidian sikao. Journal of Yanbian University.

Liu, L., \& Deng, F. (2009). Home with Kids(家有儿女)1. Beijing: Shijie tushu press.

McDonald, K.(2005). Film and Television Textual Analysis: Classroom resources. Bedfordshire: Auteur.

Shu, J. (2003). Yingshi xinshang zai duiwai hanyu jiaoxuezhong de zuoyong. Journal of Anhui Chinese Culture university.

Stempleski,S., \&Tomalin, B. (2001). Film. New York: Oxford University Press.

Tobias, C.U. (2009).The Way They Learn. Indonesia: Pionir Jaya press

Wang, X. (2005). Kandianying xuehanyu. Xi'an: Shaanxi shifan daxue Press 